\title{
REPORTS
}

\section{NATIONAL EXECUTIVE COMMITTEE REPORT}

The main attention of the National Executive Committee in recent months has been directed towards means of achieving the objectives of the Society which were adopted at the 16th Meeting of the National Council. Although many of these objectives are long-term in nature, considerable progress has been made.

\section{Scope of Practice}

The original regulations defining the Scope of the Profession of Physiotherapy were Gazetted in November 1974 and the revised version, which differed very little from the original, in December 1976.

Over the years it has become evident that the Scope, as Gazetted, does not fulfil its functiion - that of an explanatory statement which has three essential purposes

- to outline the aims and objectives of a profession

- to describe the types of service which that profession is qualifed to provide

- to provide a framework which allows latitude for professional movement and development.

Suggestions for a newly-defined Scope of Practice will, by the date of publication of this Journal, have been discussed by the National Committee of Representatives. The final version will be presented to the 17th Meeting of the National Council in April 1987 and, if approved, will be submitted to the Professional Board for Physiotherapy.

\section{Career and salary structure}

The recent across-the-board $10 \%$ increase granted to all public servants is regarded as but an interim measure, and the Society is committed to the principle of differentiation and adequate recognition of the physiotherapy profession. As usual, very late warning was received from the State regarding the most recent investigation by the Commission for the Administration. The Society was, however, in the position of being able to produce a comprehensive memorandum in time for the meeting between the Minister of Health and representatives of the Commission for Administration, due to be held on 14 April 1986.

The compilation of this memorandum was made easier as a result of the work of the various portfolio holders on the National Executive Committee, in particular those portfolios falling under the Remuneration Committee, which is a Sub-Committee of the N.E.C. Since there seems to be a certain degree of confusion regarding the role of portfolio holders, a few words of explanation may be worthwhile.

At the 16th National Council Meeting an Amendment to the Constitution was passed, providing for nomination and election of National Executive Committee Members within certain categories. In this way it is hoped that all major physiotherapy interests will gain representation on the N.E.C. Because this cannot be implemented until the next elections at the 17th National Council Meeting, members elected to the present N.E.C. were allocated certain portfolios according to their interests and expertise. Most of these portfolios fall under the aegis of one of two committees - the Education Committee or the Remuneration Committee - and their holders are therefore members of the respective committee.

The Remuneration Committee consists of the holders of the portfolios on career structure, salaries, State and Provincial Hospitals, special schools and private practice. The role of portfolio-holders and their parent committee should not be confused with the role of the Special Interest Groups/Associations of the Society. The Groups represent the interests of their members and are concerned with the provision of quality care within their interest area. They can make recommendations to or requests of the Society - via the National Executive Committee, the National Committee of Representatives or the National Council - but they have no executive function unless so authorized by the N.E.C. or by Council.

The portfolio holders are responsible for correlating information from all sources, including relevant Special Interest Groups, and submitting data and recommendations via their parent committee to the N.E.C. for implementation.

\section{Education and specialization}

Portfolios falling under the Education Committee are those on undergraduate education, post-graduate education, continuing physiotherapy education and research.

Attention is being focused on the educational processes required in order to satisfy the physiotherapy needs of the whole country. A separate portfolio has been established in order to attempt to estimate the needs of different communities. Planning will be based upon the following assumptions: 
1. That individuals should be encouraged to take responsibility for maintaining their own health.

2. That supplementary health personnel need to be trained to serve the communities in which they live.

3. That more black and coloured supplementary health personnel are urgently needed, and will be needed in increasing numbers in years to come.

4. That more health services should become community-based and geared towards the needs of that community, which are mostly third-world needs.

5. That different types of physiotherapy expertise will be needed to supply these needs, and that training courses must be structured according to the competencies which the newly qualified physiotherapy practitioner - be he professionally or practically oriented - will need to develop.

At post-graduate level, much attention is being given to the possibilities for specialization. A memorandum submitted to the N.E.C. in March is being discussed by the National Committee of Representatives in May. Possibilities include formal post-graduate degree programmes (many of which already exist), the creation of Fellowship awards (possibly administered by a College of Physiotherapists) and the more problematical system of certification of clinical competence. Although there is no doubt that specialization is desirable, its legal implications as well as limitation upon members of the profession must also be investigated.

The Society has also recently, at the request of the Department of National Health and Population Development, revised the list of qualifications recognized by the Commission for Administration and motivated for better financial recognition of additional registrable qualifications.

Progress regarding the research portfolio is reported on elsewhere in this issue.

\section{The Year of the Disabled Person}

1986 has been designated as the National Year of the Disabled Person, falling within the Decade of Disabled Persons as proclaimed by the United Nations. The Society has undertaken to promote this at local and national level, and Back Week this year will be directed towards the counselling of caretakers of disabled people.

\section{Administration and Finance}

The Society is still seeking suitable premises in which to house its Secretariat. The appointment of a permanent Secretary is also receiving attention.

S.I-C.

\section{REPORT ON ATTENDANCE AT THE SIXTH INTERNATIONAL ACUPUNCTURE SEMINAR IN HONG KONG AND ACUPUNCTURE STUDY TOUR OF MAINLAND CHINA IN OCTOBER 1985}

In August 19851 was invited to present a paper at the Sixth International Acupuncture Seminar to be held in Hong Kong from 6-8 October 1985. This seminar is an annual event organised by the International Acupuncture Society. When 1 accepted the invitation $I$ also registered for a short acupuncture study tour of mainland China which was also organised by the above Society.

The Seminar was held at the headquarters of the Hong Kong Medical Association and there were deleIgates from many parts of the world including United Kingdom, United States of America, Canada, Australia, New Zealand, India, Egypt and Jordan. Most of the delegates were medical doctors and 1 was one of two physiotherapists the other being from Australia.

The papers read at the seminar were most interesting and varied and included the use of acupuncture and/or its variants in the management of psychiatric disorders (Dr. C. Yung Associate Professor, University of Texas, U.S.A.), acupuncture for drug addiction (Dr. R. Alexander, Hong Kong), the use of acupuncture in ophthalmology (Dr R. Ching, Hong Kong), treatment of bronchial asthma using acupuncture (Dr. P. Lamoria, India), effects of acupuncture on blood cholesterol and lipids (Dr. A. Kumar, India), the application of acupuncture and acupressure in physiotherapy (Mrs. P. Tam, Senior Lecturer in Physiotherapy Hong Kong Polytechnic), the connection between acupoints and viscera through skin temperature (Dr. L. Hui Lan, Zhongshan Medical College, China) and painless labour (Dr. D. Halder, India).

My paper was entitled "A Clinical Report on the use of Acupuncture in the management of Amputation Stump Pain and Phantom Limb Pain".

This paper presented an approach to amputation stump pain which 1 have devised, and the results obtained from treating 20 amputees referred from the King Edward VIlI Hospital Amputation Rehabilitation Clinic. The subject was well received and gave rise to considerable discussion, as it did later when debated in China.

The study tour of China commenced on October 9 with a two day stay in Canton (South China). The main feature in Canton was a visit to the Zung Shan Hospital where operations using acupuncture anaesthesia were observed.

Two craniotomies (for removal of cerebral tumours) and three thyroidectomies were observed. Anaesthesia (profound analgesia) was obtained in each case by the application of electro-acupuncture (interrupted direct current of $30 \mathrm{Hertz}$ ) using two stainless steel needles. Patients had been prepared by administration of a mild sedative and omnopon or scopolamine as a pre-medication. The patients remained conscious throughout the operation and it was possible to converse with them. 
After the session in the operating theatre, long discussions were held with the Chinese anaesthetists and surgeons and the conclusions drawn in respect of acupuncture anaesthesia were, that it was given to patients who requested it and to those of a calm disposition. Its use was restricted mainly to operations above the plane of Louis. Cost was not a factor in giving acupuncture anaesthesia as modern anaesthetic apparatus and well trained anaesthetists were available.

The next three days of the tour were spent in Hangzhou where more surgical procedures involving acupuncture anaesthesia were observed. It is noteworthy that at Hangzhou Hospital 5000 craniotomies had been performed under acupuncture anaesthesia between 1975 and 1979. As well as the surgery at the Hangzhou Hospital a wide range of acupuncture procedures was as demonstrated. Acupuncture was mainly used for the management of painful musculoskeletal conditions, sinusitis, gastritis, migraine and other forms of headache.

(N.B. the World Health Organization has endorsed the use of acupuncture in the following conditions: leg ulcers, migraine, cephalgia, sinusitis, trigeminal neuralgia, vertigo, herpes zoster, neuralgia, pareses, dysmenorrhoea, bronchial asthma, colitis, amenorrhoea, duodenal and peptic ulcer).

The last two days of the tour were spent in Shanghai where further acupuncture procedures were observed at the major teaching hospital attached to the University of Shanghai.
As well as the academic programme a brief but fascinating insight into the cultural life of China was obtained. Many signs of emerging capitalism were evident and China is now open to a massive tourist trade patronised mainly by Americans and Japanese.

Medicine in China is an interesting blend of the traditional and Western. All the hospitals visited had modern (Western standard) diagnostic and treatment facilities; and all had their traditional sections (acupuncture, herbal medicine, etc.). The impression was gained that the traditional approach is still the most popular.

The seminar and tour provided a stimulating experience for me. I was able to learn several different approaches to acupuncture. I have been able to incorporate these in my practice in King Edward VIII Hospital and in the Pain Clinic at Addington Hospital. The techniques have already been taught to a number of physiotherapists who are interested in this additional method of pain modulation.

\section{Acknowledgement \\ Thanks are expressed for financial assistance from the South African Society of Physiotherapy and two col: leagues.}

\section{A. Liggins}

Senior Lecturer, Physiotherapy Department, University of Durban-Westville/Natal Provincial Administration.

\section{Try New Flotation Pads to keep you free from bedsores}

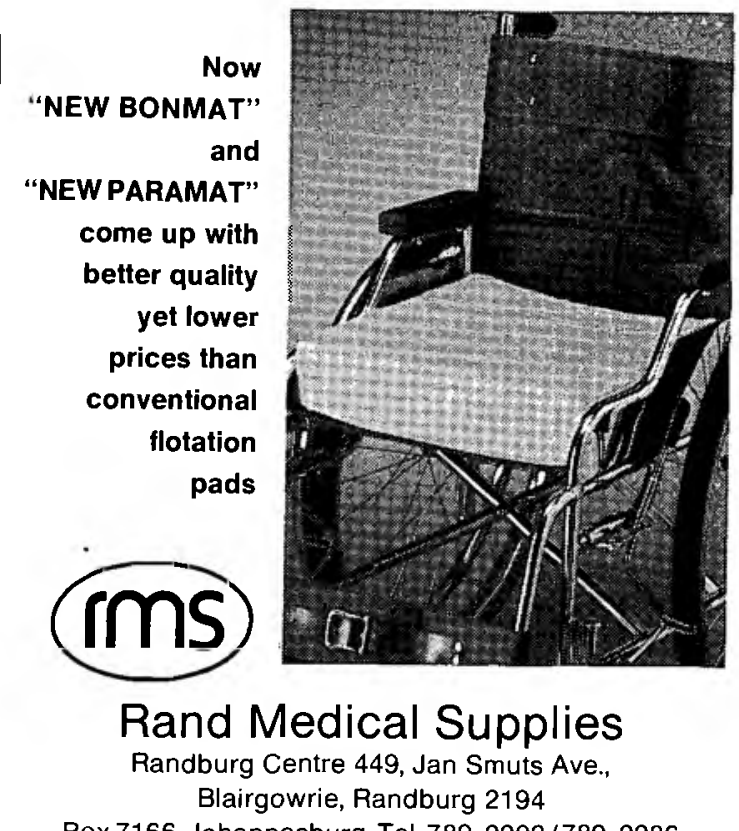

Box 7166, Johannesburg. Tel. 789-2203/789-2286 